\title{
Treatment of Drug Addicts by Psychoastrotherapy
}

\author{
M. G. Sharma ${ }^{1 *}$, Vandana Sharma ${ }^{2}$
}

\section{ABSTRACT}

The aim of the present study ascertaining the personality characteristics of treated and nontreated drug addicts, using Hindi version of the Middlesex Hospital Questionnaire and Death Anxiety Scale. 100 subjects were taken for this study out of this 50 treated and 50 non-treated drug addicts were evaluated at S.I. Mental and Physical Health Society "SIMPHS", Varanasi, district in India. Psycho-astrotherapy was given to those groups who attend the Centre for treatment. These groups were matched on the variables of age range 18-35 years with a mean age of 21.01 years. Addiction period ranged from two year to six years. The finding reveals that characteristics associated with non-treated drug addicts are anxiety, obsession, phobia, somatization, depression and hysteria, and death anxiety.

Keywords: Treatment, Drug, Psychoastrotherapy

Researchers have reported that drug addicts could be differentiated from non addicts on various personality profiles (Lodhi, 1993; Chawla et al. 1990, Doherty \& Mathews 1988, Blaszczynski et al. 1985, Kosten 1983 and Sharma \& Sharma; 2002). antisocial personality (Darke et al. 1994), alienation (Taha, 1994), expression (Moro et al. 1981), suspiciousness (Udhe et al. 1982), death anxiety (Maqbool S. 1991), anxiety (Kosten et al. 1986), aggression (Green et al. 1986), depression (Walfish et al. 1990), hysteria (Marsh et al. 1988) and somatic distress (Craig \& Olson, 1990). Effect of group behaviour on personality differences among drug addicts have also shown in a number of studies (e.g. Anglin et al. 1998; Roszell, 1987; Craig, 1979; Craig \& Olson; 1988, Sharma; 2005 and Sharma \& Sharma; 2008).

Behavioural scientists also have reported that drug addicts could be differentiated from none addicts/treated addicts on various personality profiles. Sharma \& Thakur (1989) for example, compared drug addicts and non addicts using Mithila Mental Health Status Inventory and found that drug addicts group having significantly higher scores on alienation, emotional unstability and social non conformity Psychopathic Deviate and Depression Scale scores has been

\footnotetext{
${ }^{1}$ Asstt. Professor, Dept. of Psychology, Sri Agrasen Kanya P. G. College, Varanasi, India, and Hon. Director, S. I. Mental \& Physical Health Society (SIMPHS), Chandua Chhittupur, Varanasi

${ }^{2}$ Chief Psychologist, S.I.Mental \& Physical Health Society (SIMPHS), Chandua Chhittupur, Varanasi-2, India *Responding Author (C) 2016 I M Sharma, V Sharma; licensee IJIP. This is an Open Access Research distributed under the terms of the Creative Commons Attribution License (http://creativecommons.org/licenses/by/2.0), which permits unrestricted use, distribution, and reproduction in any Medium, provided the original work is properly cited.
} 
consistently found in heroin addict, alcoholics, criminals and shoplifters (Beck \& McIntyre, 1977).

Researches on mental health in drug addicts are quite similar (Giannini et al. 1985, Sharma \& Sharma, 2003 and 2007). These studies have utilized male drug addicts. The present study also attempts to clarify that male treated heroin addicts are lower on anxiety, obsession, phobia, somatization, depression, and hysteria.

\section{Group therapy}

Group therapy is a type of psychotherapy that involves one or more therapists working with several people at the same time. This type of therapy is widely available at a variety of locations, including private therapeutic practices, hospitals, mental health clinics and community centers. Group therapy is sometimes used alone, but it is also commonly integrated into a comprehensive treatment plan that also includes individual therapy and medication.

In The Theory and Practice of Group Psychotherapy, Irvin D. Yalom outlines the key therapeutic principles that have been derived from self-reports from individuals who have been involved in the group therapy process (Yalom and Lesczc 2005).

\section{Procedure}

Groups can be as small as three or four people, but group therapy sessions generally involve around seven to twelve individuals (although it is possible to have more participants). The group typically meets once or twice each week for an hour or two.

According to Oded Manor the minimum number of group therapy sessions is usually around six, but a full year of sessions is more common (Manor, 1994). Manor also notes that these sessions may either be open or closed. In open sessions, new participants are welcome to join at any time. In a closed group, only a core group of members are invited to participate.

So what does a typical group therapy session look like? In many cases, the group will meet in a room where the chairs are arranged in a large circle so that each member can see every other person in the group (Manor, 1994). A session might begin with each member of the group introducing themselves and sharing why they are in group therapy, or members might share their experiences and progress since the last meeting.

The specific manner in which the session is conducted depends largely on the goals of the group and the style of the therapist. Some therapists might encourage a more free-form style of dialogue, where each member participates as he or she sees fit. Other therapists might have a specific plan for each session that might include having clients practice new skills with other members of the group. 


\section{Astrotherapy:}

Astrology is a combination of science and metaphysics. To make a map and erect a horoscope from the birth particulars is a scientific process requiring considerable expertise, skill and application.

As we know that planets directly effect on our body and mind, and the water plays an important role to balance in human body, which was influenced by the moon. This water- balance, on the other hand, controls our body and mind. Similarly many ailments are caused by the adverse planetary impact on the moon, e.g., influenza, chronic coughs and colds, bronchitis, tuberculosis, asthma, nervous tensions, gout, sciatica, etc. A weak moon in a birth chart can also create lunatics. An adverse or weak moon causes psychological- disorders and it has been observed that the problems of psychic patients are accentuated on new moon days and full moon days. The astro-sciences, like a clinical psychologist, guide you. Say, if your birth charts has been correctly drawn and carefully analyzed and interpreted. It can fairly reveal what would be your basic characteristics, likes and dislikes marital harmony or discord, your level of intellect and many such related matters including love life, professional achievements, honours and distinctions. A systematic study of astro-science goes a long way in getting the best out of one's life and helping one to sail through turbulent times.

\section{Psychoastrotherapy:}

Combination of psychotherapy and astrotherapy is known as psychoastrotherapy. Psychoastrotherapy is a new technique which has been developed for the treatment of mental patients. The position of planets in horoscope plays an important role to the origin of mental sickness. So, knowledge of astrology is must for any clinical psychologist besides psychotherapy. At present era science has proved that planets are directly/indirectly effect on human's body and mind. After the analysis of horoscope and the position of planets appropriate suitable stones and Indian Vedic Mantra as well as psychotherapy were used for the treatment of mental patients (Sharma and Sharma, 2013)

\section{METHOD}

\section{Sample:}

50 treated and 50 non-treated drug addicts were evaluated at S.I. Mental and Physical Health Society (SIMPHS) and Drug De-addiction Center, Varanasi, India. The age group was 18 to 35 years with a mean age of 21.01 years. The sample was incidental random one, addiction period ranged from three to six years. They were treated by expert psycho-astrotherapist. Non-treated subjects were included in this study those had not taken any type of treatment and they attend first time to the center. Middlesex Hospital Questionnaire (Baht \& Srivastava, 1973) and Thakur \& Thakur 1985). 


\section{RESULTS AND DISCUSSION:}

With a view to comparing mean scores of treated and non-treated drug addicts on mental health were analyses using ' $t$ '-test of significance. Results are presented in the following table-1-2.

Scores obtained by the two groups on anxiety, obsession, phobia, somatization, depression and hysteria were analyzed using ' $t$ '-test of significance and results are shown in the following table No.1

Table-1,Comparison of treated and non-treated drug addicts on anxiety, obsession, phobia, somatization, depression and hysteria variables.

\begin{tabular}{|l|l|l|l|l|l|l|l|}
\hline \multirow{2}{*}{$\begin{array}{l}\text { Variables/ } \\
\text { Questionnaire }\end{array}$} & \multicolumn{2}{|c|}{$\begin{array}{c}\text { Treated drug } \\
\text { addicts }\end{array}$} & \multicolumn{2}{c|}{$\begin{array}{c}\text { Non-treated drug } \\
\text { addicts }\end{array}$} & \multirow{2}{*}{ 't'-value } & \multirow{2}{*}{ df. } & p. \\
\cline { 2 - 9 } & M & SD & M & SD & & & \\
\hline Anxiety & 2.18 & 1.01 & 3.99 & 1.05 & 8.82 & 98 & .01 \\
\hline Obsession & 4.92 & 1.35 & 6.41 & 1.13 & 6.00 & 98 & .01 \\
\hline Phobia & 5.01 & 1.01 & 4.41 & 1.07 & 2.88 & 98 & .01 \\
\hline Somatization & 4.73 & 1.11 & 6.04 & 1.19 & 5.69 & 98 & .01 \\
\hline Depression & 4.83 & 1.07 & 5.93 & 1.23 & 4.65 & 98 & .01 \\
\hline Hysteria & 4.33 & 1.30 & 5.23 & 1.26 & 3.51 & 98 & .01 \\
\hline Mental Health (MHQ) & 26.00 & 6.85 & 32.01 & 6.93 & 4.36 & 98 & .01 \\
\hline
\end{tabular}

It is obvious from the above table that mean value of treated and non-treated drug addicts do differ significantly on six variables i.e. anxiety, obsession, phobia, somatization, depression and hysteria. The treated group of drug addicts has lower mean value on anxiety, obsession, somatization, depression, phobia and hysteria variables and total mental health. Roszell (1987), Cernovsky (1986) and Viney (1985) found in their study that drug addicts had scored higher on anxiety, and depression than the non addicts. Wurmser (1987), Walfish et al. (1990), Craig et al. (1990), Montoya et al. (1994), Marsh et al. (1988) and Sharma \& Sharma (2007) have reported in their study that non treated drug addicts were associated with phobia, anxiety, somatic distress, depression, hysteria in comparison to the treated drug addicts.

This finding is quite similar to the previous study of Sharma and Sharma (2007) that non-treated drug addicts do have significantly higher on anxiety, obsession, somatization, depression, hysteria. 
Table-2, Table no. 2: Comparison of treated and non-treated drug addicts on death-anxiety

\begin{tabular}{|l|l|l|l|l|l|l|l|}
\hline \multirow{2}{*}{ Scale } & \multicolumn{2}{|l|}{ Treated Drug addicts } & \multicolumn{2}{|l|}{ Non-treated Drug addicts } & 't'- & \multirow{2}{*}{ df. } & p. \\
& $\mathbf{M}$ & vD & $\mathbf{M}$ & SD & value & & \\
\hline Death -anxiety & 49.00 & 4.10 & 55.3 & 3.99 & & 98 & .01 \\
\hline
\end{tabular}

A perusal of table no. 2 that treated drug addicts have scored lower on death anxiety than the non-treated drug addicts and this difference was significance at or beyond .01 level of confidence. This result indicates that treated drug addicts have lower range of death-anxiety in comparison to the non-treated drug addicts. Such person would not meet people easily, would not feel comfortable with strangers and would experience sever stage fright. Such people might have serious interpersonal disturbance in the adjustment patterns. The present study is quite similar to the previous findings of Maqbool (1991) revealed in his study on the same scale that non-treated drug addicts have significantly higher mean value in comparison to the drug addicts.

\section{REFERENCES:}

Anglin M. Douglas, Ryan, Timothy, M. Booth, Mary, W. \& Hsear, Yih-ing (1998). Ethinic differences in narcotic addiction: Characteristics of Chicago and Anglo methadone maintenance clients. International Journal of the Addiction 32, 125-149.

Blaszczynski, A.P., Buhrich, N. \& Mc Conaghy, N. (1985). Pathological gamblers, heroin addicts and controls compared on the E.P.Q. "Addiction Scale”. Britis Journal of Addiction 80, 315-319.

Beck, E.A. Mc Intyre, S. C. (1977). MMPI Patterns of shoplifters within a college population. Psychological Reports, 43, 1035 - 1040.

Baht, V.K. \& Srivastava O.N. (1973), Hindi version of the Middlesex Hospital Questionnaire, I.M.S. (B.H.U.), India.

Cernovsky, Zdnek, C. (1986). Colour preference and MMPI scores of alcohol and drug addicts. Journal of Clinical Psychology, 42, 668-668.

Chawla, Shashi G., Bhushan, HM \& Kacker, Chitra (1990). Eysenck Personality Questionnaire scores of heroin addiction in India. Indian Journal of Psychiatry, 32(1), 25-29.

Craig, R.J. \& Olson, Ronald, E. (1988). Changes in function ego states following treatment of drug abuse. Transactional Analysis Journal. 18(1) 6-26.

Craig, R.J. \& Olson, Ronald, E. (1990). MCMI comparison of cocaine abusers and heroin addicts. Journal of Clinical Psychology 6(2), 230-237.

Craig, R.J. (1979). Personality characteristics of heroin addicts. A review of the empirical literature with critique-part II. International Journal of the Addiction, 14, 606-628.

Darke, Shane, Swift. Wendy \& Hall, Wayne (1994). Prevalence severity and correlates of psychological morbality among methadone maintenance clients., 89(2), 211-217.

Doherty, Conagh \& Mathews, Gerald (1988). Personality characteristics of opiate addicts. Personality of Individual Differences, 9(1), 171-172. 
Giannini, A.J. \& Jone, T. (1985). Decreased perception of non verbal cues in heroin addicts. Journal of Psychology. 119(5), 455-459.

Green, P.D. (1986). Associative response to double entendre drug words : A study of drug addicts and college students. Personality \& Social Psychology. Bulletin, 12(1), 31-39.

Kosten, Thomas R. et al. (1986). Cocaine abuser among opioid : demography and diagnostic factors in treatment. American Journal of Drug \& Alcohol abuse, 12(1-20), 10-16.

Kosten, Thomas R. et al. (1983). The depression of the Modusley Personality Inventory to depression in addicts. Comprehensive Psychology, 26(4), 5.5-542.

Lodhi, P.H. \& Thakur, Sangeeta (1993). Personality of drug addicts Eysenckian analysis. Personality and individual Differences, 15(2), 121-128.

Maqbool, S. (1991). Influence of health related variables on death-anxiety among drug addicts Journal of Personality and Clinical Studies, 7(1), 31-36.

Marsh, D.T., Stile, S.A., Stoughton, Nancy, L. \& Tout-Landen, Beth, (1988). Psychopathology of opiate addiction. Comparison data from the MMPI and MCMI. American Journal of the Drug and Alcohol Abuse, 14(1), 17-27).

Moro, B.E. \& Sardena, M. (1981). Methods of a diagnostic approach to heroin dependence: A preliminary study of 5 subjects. Psychiatria benerale Della et. evaluate, 19(13), 247-263.

Montoya, Ivan D. Hess, Judith M. Covi. Lino, Fudala, Paul J. et.al. (1994). A comparative study of psychopathology functions between cocaine and opiate dependent patients. American Journal of Addiction, 3(1), 36-42.

Roszell, D.K. \& Calsyn, D.A. (1987). Methadone dosage : Patients characteristics and clinical correlates. International Journal of the Addiction, 21(11), 1233-1246.

Sharma, M.G. \& Thakur, G.P. (1989). Mental health status and drug addiction, Proceedings of the International Congress for Drug abuse Prevention and Control, Bombay, 14-16 Apr.

Sharma, M.G. \& Sharma, V. (2002). Personality characteristics of treated and untreated drug addicts, Proceeding in the National Seminar on Psychological Well- Being, Varanasi, India.

Sharma, M.G. \& Sharma, V. (2003). Mental health status of drug addicts, Perspectives in Psychological Researches Vol. 24, 25 \& 26(1-2), 52-56.

Sharma, M.G. \& Sharma, V. (2004). Death anxiety and locus of control of drug addicts and non addicts. Perspectives in psychological researches Vol. 27 \& 28, 105-107.

Sharma, M.G. \& Sharma, V. (2004). Personality characteristics and drug addiction. Perspective in Psychological Researches, Vol. 27 \& 28, 121-123.

Sharma, M.G. (2005). A comparative study of the personality characteristics of drug addicts and non-addicts. Indian Psychological Review, 64(3), 137-142.

Sharma, M.G. \& Sharma, V. (2007). Mental health and death anxiety between pre treated and post treated narcotic addicts. The Asian Journal of Psychology \& Education Vol. 40(1-2), 36-40.

Sharma, V. Upadhyay, A. \& Sharma, M.G. (2008), Personality differences between treated and non treated charas addicts, SIS Journal of Projective Psychology \&Mental Health, Vol. 17(2). 
Sharma, M.G. \& Sharma, V. (2013). Psycho-astrotherapy and vipassna meditation for pathological gambling. Lap-Lambert Academic Publishing House, Germany. Taha, Amir, (1994). Personality study of alcohol, heroin and poly drug abuser in an Arabian Gulf population. Psychological Reports, 72, 515-520.

How to cite this article: M Sharma, V Sharma (2016) Treatment of Drug Addicts by Psychoastrotherapy, International Journal of Indian Psychology, Volume 3, Issue 3, No. 5, DIP: 18.01.082/20160303 